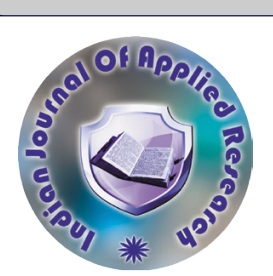

\title{
Oncology
}

\section{ADHERENCE TO ANTIEMESIS GUIDELINES IN A DAY CARE CHEMOTHERAPY UNIT: EXPERIENCE FROM A TERTIARY CARE CENTRE}

\section{Arun Philip}

\section{Sahil Bambroo}

\section{Pavithran} Keechilat*
Assistant Professor, Department of Medical Oncology, Amrita Institute of Medical Sciences, Ponekkara, Kochi, India

Assistant professor, Department of Medical Oncology, Amrita Institute of Medical Sciences, Ponekkara, Kochi, India

Professor, Department of Medical Oncology, Amrita Institute of Medical Sciences, Ponekkara, Kochi, India. *Corresponding Author

ABSTRACT Among the side effects of cancer therapy, chemotherapy induced nausea and vomiting (CINV) is the most distressing and it affects the quality of life of patients and the treatment outcome. The study was undertaken to audit the adherence to antiemesis guidelines in the day care chemotherapy unit at our centre. A vast majority of our chemotherapies $(85 \%)$ were high emetic risk regimes. We found that the adherence to anti-emesis guideline was $57 \%$. Among the cases of non adherence, a majority were over-treated (57\%).

Looking into the reasons of non adherence, we feel the need to evolve our own population based guidelines. Improving public awareness about the toxicities of chemotherapy will help in dispelling unwanted fear of toxicity. Improving awareness about anti-emetic guidelines among clinicians also will play a major role in improving adherence to guidelines and thus improving outcome of therapy.

KEYWORDS : CINV, Anti-emetics, Awareness

\section{INTRODUCTION}

Cancer is one of the most dreaded diseases of our times and part of the reason it is so feared is the fact that the treatment of cancer is perceived to be very toxic. Among the side effects of cancer therapy, chemotherapy induced nausea and vomiting (CINV) is the most distressing., Uncontrolled emesis affects quality of life and compliance to therapy. It has also been reported in studies that a significant number of patients delay or discontinue therapy because of uncontrolled CINV. ${ }^{3}$ Hence it is of utmost importance that patients on chemotherapy receive appropriate anti-emetics to control their emesis. It has been observed that adherence to anti-emesis guidelines have improved nausea and vomiting to a good extent. ${ }^{4}$ Hence, we undertook the study to audit the adherence to antiemetic guidelines at our day care chemotherapy unit

\section{METHODS}

The chemotherapy administration charts of 150 consecutive patients, who received their first cycle of chemotherapy at the day care chemotherapy unit over a 6 week period at our centre were accessed and the relevant data recorded. The age, sex, malignancy being treated, the chemotherapy drug / schedule administered, the antiemetic drugs prescribed were captured. The chemotherapy schedule used for each patient was classified based on their emetogenic risk as either minimal, low, moderate or high. This was based on the standard anti-emesis guidelines published by the national comprehensive cancer network $(\mathrm{NCCN}){ }^{5}$ As per this guideline, a high emetogenic risk chemotherapy is one where the risk of emesis is more than $90 \%$ in the absence of effective antiemetic prophylaxis. With moderate, mild and minimal emetic risk chemotherapy schedules, the risk of emesis is 30-90\%, 10$30 \%$ and less than $10 \%$ respectively. ${ }^{5}$ As part of the same guideline, each emetogenic risk category entails the use of a combination of antiemetic drugs. The emetogenic risk categories, the common chemotherapies included in each category and the preferred antiemetic regime for each category is listed in table 1 .

Table 1: Anti-emetic risk categories \& the preferred anti-emetic agents (Adapted)

\begin{tabular}{|c|l|c|}
\hline $\begin{array}{c}\text { Emetic } \\
\text { Risk }\end{array}$ & \multicolumn{1}{|c|}{$\begin{array}{c}\text { Common drugs / schedules } \\
\text { included }\end{array}$} & $\begin{array}{c}\text { Preferred anti-emetic } \\
\text { regime }\end{array}$ \\
\hline Minimal & $\begin{array}{l}\text { Vincristine / Vinblastine / } \\
\text { Vinorelbine } \\
\text { Bevacizumab / Cetuximab / } \\
\text { Ramucirumab } \\
\text { Decitabine } \\
\text { Pertuzumab } \\
\text { Pembrolizumab / Nivolumab / } \\
\text { Atezolizumab } \\
\text { Bortezomib / Daratumumab } \\
\text { Rituximab / Bleomycin / } \\
\text { Asparaginase } \\
\text { Cytarabine }<100 \mathrm{mg} / \mathrm{m}^{2}\end{array}$ & \\
\hline \hline
\end{tabular}

Submitted : $12^{\text {th }}$ August, 2019 Revised : $21^{\text {st }}$ September, 2019

\begin{tabular}{|c|c|c|}
\hline Low & $\begin{array}{l}\text { Docetaxel / Paclitaxel /Albumin } \\
\text { bound Paclitaxel } \\
\text { Gemcitabine / Ixabepilone / } \\
\text { Mitomycin } \\
\text { Carfilzomib } \\
\text { Ado Trastuzumab } \\
\text { Eribulin } \\
\text { Carboplatin AUC }<4 \\
\text { Cytarabine 100-200mg/m² } \\
\text { Arsenic Trioxide } \\
\text { Pemetrexed }\end{array}$ & \begin{tabular}{|l} 
* Ondansetron / \\
Granisetron \\
OR \\
*Dexamethasone $12 \mathrm{mg}$ \\
iv OR \\
*Metochlopromide \\
10mg iv
\end{tabular} \\
\hline Moderate & $\begin{array}{l}\text { Carboplatin AUC }<4 \\
\text { Dacrbazine / Melphalan } \\
\text { Irinotecan / Idarubicin / } \\
\text { Daunomycin } \\
\text { Cytarabine }>200 \mathrm{mg} / \mathrm{m}^{2} \\
\text { Cyclophosphamide }<1500 \mathrm{mg} / \mathrm{m}^{2} \\
\text { Ifosphamide }<2 \mathrm{gm} / \mathrm{m}^{2} / \\
\text { Oxaliplatin } \\
\text { Adriamycin }<60 \mathrm{mg} / \mathrm{m}^{2} / \\
\text { Epirubicn }<90 \mathrm{mg} / \mathrm{m}^{2} \\
\text { Temozolamide / Methotrexate }> \\
250 \mathrm{mg} / \mathrm{m}^{2}\end{array}$ & $\begin{array}{l}\text { * Ondansetron / } \\
\text { Palanosetron / } \\
\text { Granisetron } \\
+ \\
\text { * Dexamethasone } 12 \mathrm{mg}\end{array}$ \\
\hline High & $\begin{array}{l}\text { Anthracycline }+ \\
\text { Cyclophosphamide } \\
\text { Adriamycin }>60 \mathrm{mg} / \mathrm{m}^{2} / \\
\text { Epirubicn }>90 \mathrm{mg} / \mathrm{m}^{2} \\
\text { Carboplatin AUC }>4 \\
\text { Cisplatin } \\
\text { Dacrbazine } \\
\text { Cyclophosphamide }>1500 \mathrm{mg} / \mathrm{m}^{2} \\
\text { Ifosphamide }>2 \mathrm{gm} / \mathrm{m}^{2}\end{array}$ & $\begin{array}{l}\text { * Aprepitanit / } \\
\text { Fosaprepitant / } \\
\text { Netupitant } \\
+ \\
* \text { Ondansetron / } \\
\text { Palanosetron / } \\
\text { Granisetron } \\
+ \\
* \text { Dexamethasone } 12 \mathrm{mg} \\
+/ \text { - } \\
* \text { Olanzapine }\end{array}$ \\
\hline
\end{tabular}

\section{AUC : Area under curve}

Once the emetogenic risk was identified, the antiemetic drugs the patient received was checked to see if it was in accordance with the guideline. In the same manner the adherence to the antiemetic guideline was checked for the whole cohort of 150 patients. If a non adherence was detected, the next step was to identify whether it was over- treatment or under-treatment based on the number of antiemetic drugs administered. Thus the adherence to the guidelines for the whole group was calculated as a percentage. We went a step further and tried to assess the reasons behind the deviation from guidelines. This was done by means of review of the electronic medical records for a 
documented reason, interview of the clinician and the oncology nurses. The efficacy of the antiemetic medicines is not being reported here as the aim of the study was to audit the adherence to antiemetic guidelines in the day care chemotherapy unit and to ascertain the reasons for non-adherence

\section{RESULTS}

The chemotherapy administration charts of 150 patients were retrieved for the study. Patients receiving non cytotoxic therapy like bisphosphonates, iron products, erythropoietin, growth factors, intravenous immunoglobulins were not included in the study. Of the 150 patients, 79 were female and 71 male. The median age of the study population was 59 years (1-77yrs). The baseline characteristics of the study group is represented in table 2 .

Table 2: Baseline characteristics

\begin{tabular}{|c|c|}
\hline Study population (N) & 150 \\
\hline Median Age (years) & $59(1-77)$ \\
\hline Sex distribution (M:F) & $71: 79$ \\
\hline Emetogenicity of the chemo schedule & $(\mathrm{N})$ \\
High & 85 \\
Moderate & 49 \\
Low & 10 \\
Minimal & 06 \\
\hline
\end{tabular}

The most common malignancy encountered was Breast cancer. The most common chemotherapy regime encountered in the study group was the combination of paclitaxel and carboplatin followed by Adriamycin and cyclophosphamide. A vast majority of the chemotherapy schedules fell into the high risk category as far the emesis risk was concerned. Out of the 150,85 schedules were categorized as highly emetogenic; 49 were moderate emetic risk chemotherapy schedules, 10 were low risk and 6 in the minimal emetogenic risk category. Among the whole cohort, when the antiemetics administered was checked, it was seen that the adherence to guideline was $57 \%$ ( 85 schedules). In the remaining $43 \%$ (65 schedules), there was a deviation from the anti-emetic guideline as proposed by the NCCN ( Table 3 ).

On further analysis into the type of deviation, it was found that 37 out of the $65(57 \%$ ) deviations were overtreatment and the remaining $43 \%$ were under-treatment. Overtreatment meant that the patient received an antiemetic regime that was in excess of what is recommended and undertreatment meant they received suboptimal antiemetic medications.

Table 3: Adherence to guideline \& type of non-adherence

\begin{tabular}{|c|c|c|}
\hline Adherence to guideline $(\mathbf{N}=\mathbf{1 5 0})$ & $\mathbf{N}$ & $\mathbf{\%}$ \\
\hline Yes & 85 & 57 \\
\hline No & 65 & 43 \\
\hline Type of Non-adherence $(\mathbf{N}=\mathbf{6 5})$ & $\mathbf{N}$ & $\mathbf{\%}$ \\
\hline Over-treatment & 37 & 57 \\
\hline Under-treatment & 28 & 43 \\
\hline
\end{tabular}

In $42 \%$ of cases, the reason for non adherence could not be ascertained. Among the cases where a reason was found (58\%), the most common cause for non adherence was physician's discretion $(60 \%)$. A good number of over-treated patients were deemed by the clinician to be candidates for antiemetic therapy in excess of what the guideline prescribed. Another predominant reason (25\%) was patients request due to fear of emesis. The remaining 'overtreatments' were due to lack of awareness of guidelines. Among the cases who were undertreated, many of them were again due to physician's discretion, where he felt that the particular chemotherapy regime did not require stiff anti-emetics based on his previous clinical experience. A good number was due to lack of awareness of guidelines. A small proportion of patients cited logistics as a reason for getting under-treatment. This was particularly noticed in Cisplatin based chemotherapies, where the antiemetic (NK1 inhibitors) is costlier than the chemotherapy drug itself.

\section{DISCUSSION}

It is very evident that chemotherapy induced nausea and emesis significantly affects the quality of life and the productivity of a patient on anticancer therapy. ${ }^{6}$ Several studies suggest that it can affect the compliance to therapy and increases the rates of withdrawal from a curative treatment protocol. ${ }^{7}$ It is important to understand the cause of CINV in order to tackle it effectively.

\section{Pathophysiology of CINV}

CINV may be broadly classified as Acute (Occurring within the first day of therapy) or delayed (Occurring after 24 hours and my last up to a week). ${ }^{8}$ Vomiting is the result of the interplay of various stimuli that travel back and forth between the emesis centre (Medulla), the chemoreceptor trigger zone (CTZ), the gastrointestinal tract and the cerebral cortex. Impulses from the higher centres via vagal efferents, reaching the salivation center, abdominal muscles and respiratory center finally culminate in an episode of emesis. ${ }^{9}$ The various neurotransmitters that are involved in the genesis of nausea and emesis are serotonin(5HT3), $\gamma$-aminobutyric acid (GABA), dopamine, substance $\mathrm{P}^{10}{ }^{10}$ The newer anti-emtic agent Aprepitant is directed against the Neurokinin 1, which is thought to be a cardinal member in the CINV pathway. ${ }^{11}$

It is clear that adherence to anti-emesis guidelines play a major role in the comprehensive care of the cancer patient leading to better compliance and subsequently better outcome. The anti-emesis guidelines have been formulated based on the emetogenic risk of the various chemotherapy drugs and combinations. Aapro et al in the study done few years back proved that adherence to antiemetic guidelines result in significantly better control of nausea and emesis. ${ }^{4}$ In a study reported from the United states, the adherence to antiemetic guidelines, audited among the medium emetogenic chemotherapy regimes alone, was found to be $58 \%{ }^{12}$ In this audit as well, the adherence was $57 \%$ in the whole study population, which was very comparable. Multiple studies done world over reveal the fact that the adherence to anti emetic guideline is poorer than expected. Many clinicians and care givers have looked at the possible reasons. Snow et al, in an audit among oncology nurses, reported that a multitude of reasons; ranging from physician preference, costs of drugs, patient preference, lack of awareness of guideline recommendations, to availability of drugs, contributed to poor adherence to anti emetic guidelines. ${ }^{13}$ The most common response they gathered in this regard was physician preference. In a good number of cases, the clinician was satisfied with their current antiemetic prescriptions. Cost of medicines / insurance coverage was the reason listed third in the list. ${ }^{13}$

The reasons of deviation from guideline in our own population was not hugely different. As in the data from west, physician's discretion was the most commonly attributed reason for non adherence. One point of difference from the western data is that a lot more of our patients requested stiffer anti-emetics, where it was probably not needed. This probably just reflects the fear of toxicity of chemotherapeutic drugs, which are deep rooted in our population. In quite a number of cases, the physician undertreated patients, where he felt that the particular chemotherapy regime did not require stiff anti-emetics based on his previous clinical experiences. This probably indicates that we should evolve our own data on the emetogenic risk of chemotherapeutic regimes in our population and formulate guidelines accordingly rather than just follow western guidelines. Lack of awareness of guidelines is an issue that can be addressed. An audit-feedback response was instituted and measures were taken to improve the awareness of guidelines among the practicing clinicians, especially among the residents in the department.

In conclusion, the adherence to anti-emetic guidelines in the day care unit is not encouraging. The reasons of non adherence points towards the need for evolving our own population based guidelines and more effective control of emesis. Improving public awareness about the toxicities of chemotherapy will help in dispelling unwanted fear of toxicity. Improving awareness among clinicians also will play a major role in improving adherence to guidelines and thus improving outcome of therapy.

\section{REFERENCES}

1. Hesketh PJ. Comparative review of 5-HT3 receptor antagonists in the treatment of acute chemotherapy-induced nausea and vomiting. Cancer Invest 2000; 18:163-173.

2. Coates A, Abraham S, Kaye SB et al. On the receiving end - patient perception of the side-effects of cancer chemotherapy. Eur J Cancer Clin Oncol 1983; 19:203-208.

3. Ritter Jr HL, Gralla RJ, Hall SW et al. Efficacy of intravenous granisetron to control nausea and vomiting during multiple cycles of cisplatin-based chemotherapy. Cancer nausea and vomiting during
Invest 1998;16:87-93

4. Aapro M, Molassiotis A, Dicato M, et al: The effect of guideline-consistent antiemetic therapy on chemotherapy-induced nausea and vomiting (CINV): The Pan European Emesis Registry (PEER). Ann Oncol 23:1986-1992, 2012

5. Clinical practice guidelines in oncology - v.1.2019. National Comprehensive Cancer Network. http://www.nccn.org/professionals/physician_gls/PDF. Accessed Aug 18th, 2019.

6. McDonagh M, Peterson K, Thakurta S. Consideration of evidence on antiemetic drugs for nausea and vomiting associated with chemotherapy or radiation therapy in adults. Rockville (MD); 2010. 
7. Richardson JL, Marks G, Levine A. The influence of symptoms of disease and side effects of treatment on compliance with cancer therapy. J Clin Oncol 1988;6:1746-1752

8. Roscoe JA, Morrow GR, Hickok JT, et al. Biobehavioral factors in chemotherapyinduced nausea and vomiting. J Natl Compr Canc Netw. 2004; 2:501-508.

9. American Gastroenterological Association medical position statement: nausea and vomiting. Gastroenterology 2001;120:261-263.

10. Navari RM. Pharmacological management of chemotherapy-induced nausea and vomiting: focus on recent developments. Drugs. 2009; 69:515-533

11. Hesketh PJ, Grunberg SM, Gralla RJ, et al. The oral neurokinin-1 antagonist aprepitant for the prevention of chemotherapy-induced nausea and vomiting: a multinational, randomized, doubleblind, placebo-controlled trial in patients receiving high-dose cisplatin - the Aprepitant Protocol 052 Study Group. Journal of Clinical Oncology. 2003;21:4112.

12. Affronti ML1, Schneider SM, Herndon JE 2nd, Schlundt S, Friedman HS. Adherence to antiemetic guidelines in patients with malignant glioma: a quality improvement project to translate evidence into practice. Support Care Cancer. 2014 Jul;22(7):1897-905. doi: 10.1007/s00520-014-2136-0. Epub 2014 Feb 26

13. Clark Snow R, Affronti ML, Rittenberg CN. Chemotherapy-induced nausea and vomiting and adherence to antiemetic guidelines: results of a survey of oncology nurses. Support Care Cancer (2018).26:557-564 